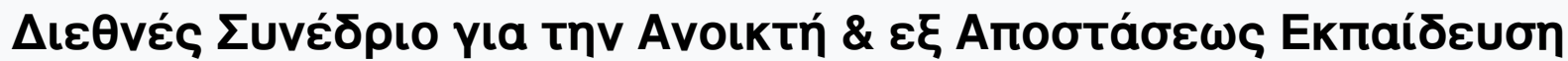

Tón. 6, Ap. 1A (2011)

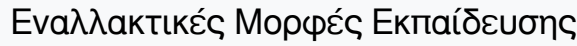

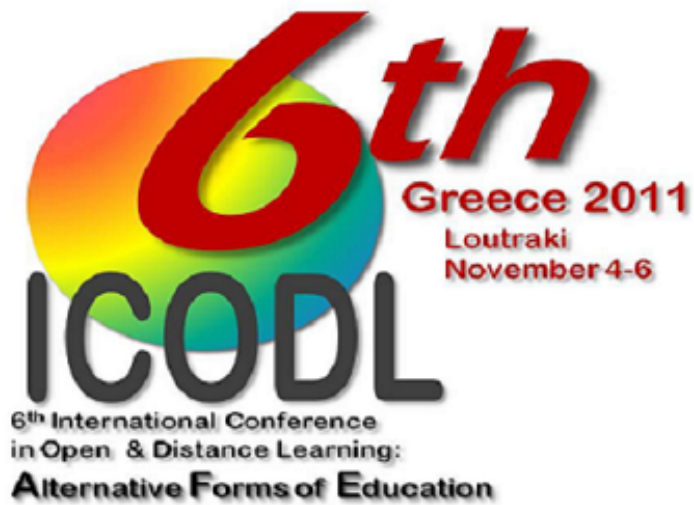

Blending Distance Learning Platforms and 3D Virtual Learning Environments

Ioannis Kostarikas, Iraklis Varlamis, Andreas Giannakoulopoulos

doi: $10.12681 /$ icodl.699

TOMOEA

PART/MEPOEA 


\title{
Blending Distance Learning Platforms and 3D Virtual Learning Environments
}

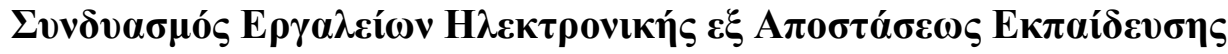

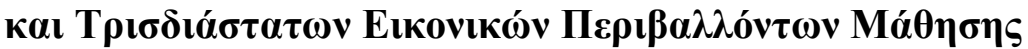

\author{
Ioannis Kostarikas \\ MSc in Virtual \\ Communities, Panteion \\ University, \\ Dept. of Psychology \\ ykostarikas@gmail.com
}

\author{
Iraklis Varlamis \\ Harokopio University of \\ Athens \\ Dept. of Informatics \& \\ Telematics \\ varlamis@hua.gr
}

\author{
Andreas \\ Giannakoulopoulos \\ Ionian University \\ Dept. of Audio \& Visual \\ Arts \\ agiannak@ionio.gr
}

\begin{abstract}
The paper at hand seeks to investigate whether virtual reality and distance learning tools can be combined in order to effectively support the learning process. This research deviates from related research works which study whether the distance learning tools and / or three-dimensional virtual learning environments can support existing learning communities and complement the traditional lesson in the classroom. Contrary to those studies, this one focuses on open learning communities whose members have the opportunity to meet only online and investigates whether the existence of a 3D environment can be combined smoothly and productively with the already established tools for online learning communities support. Firstly, this paper presents the characteristics of the 3D platform that was used and those of a web-based e-learning platform, and focuses on the points of potential interconnection between them. Secondly, it describes the key points of the e-learning community that was studied and the difficulties experienced during the implementation of the project. Finally, it presents details of the procedure followed for the evaluation of this effort and summarizes the conclusions reached.
\end{abstract}

\section{Пврі́ $\eta \psi \eta$}

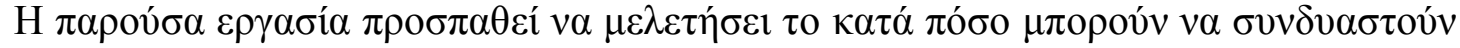

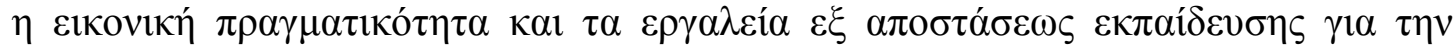

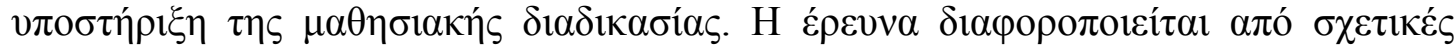

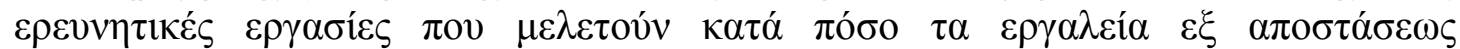

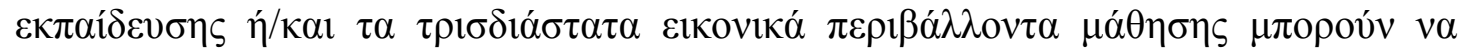

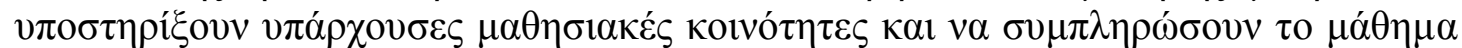

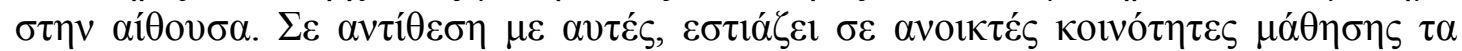

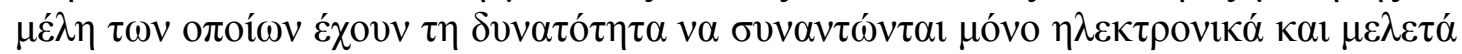

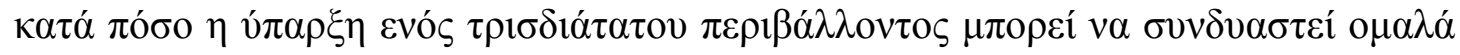

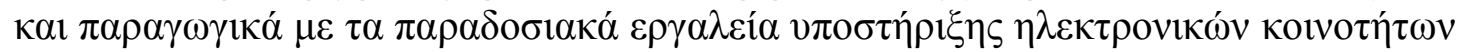

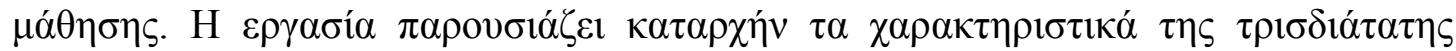

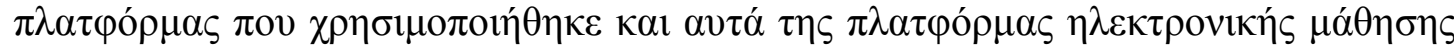

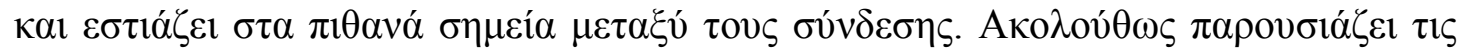

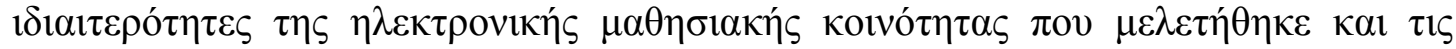

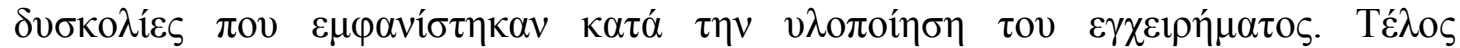




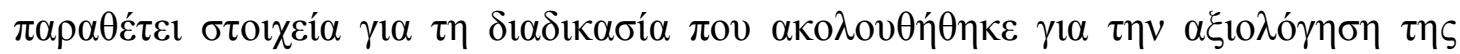

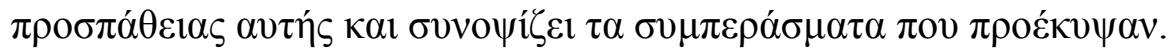

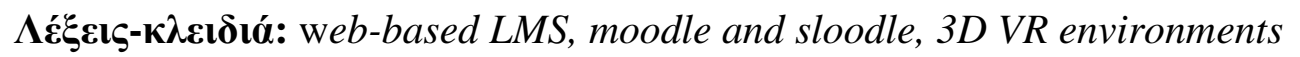

\section{Introduction}

The motivating idea of our work is to create a community for teaching various Physical Science topics and exploit the capabilities of 3D virtual environments (3DVEs) to the maximum. For this reason, we designed a series of courses on different disciplines, such as chemistry, physics and astronomy, which can be significantly favored by $3 \mathrm{D}$ visualizations and the use of multimedia. Since the community members live in different places and join the community in their free time, a distant learning approach must be followed. However, we use 3DVEs in order to create our community member the sense of being in a classroom. For this reason, apart from the basic e-learning platform, where students can access educational content and activities and communicate and cooperate with others from distance, we created a 3D virtual classroom representation and arranged weekly meetings for the community members. In this virtual classroom, members meet face to face, or at least avatar to avatar. Teachers give lectures that simulate lectures in the classroom, answer to students' questions and motivate students to use the educational material and additional web resources. The final result is an application of the blended learning model (Graham, 2005) (Trapp, 2006) in a virtual learning community.

This paper presents the technical details of our educational platform, which combines the merits of an open source e-learning platform (Moodle) and a 3D virtual environment (SecondLife - SL) and discusses our initial findings from the evaluation of the first course. It examines the interestingness and usefulness of the blended learning approach, and the students' impressions from the simulation of the traditional learning model in the virtual environment.

The following section presents some related research works that introduce 3DVEs in the learning process. In section 3, we provide details on the design of our first course. Section 4 highlights the most important implementation issues and section 5, illustrates the students' impressions from an educational, psycosociological and technological aspect. Finally, section 6 presents our first conclusions and summarizes our next steps.

\section{Related work}

The aim of virtual learning communities is to collaboratively improve knowledge in the field of expertise of the community. In the case of open learning communities everyone is allowed to participate and either offer or consume the collective knowledge (Kommers et al, 2003). Although e-learning (distant learning) approaches are gaining the hype, since they provide synchronous means of interaction between students and teachers, blended solutions are preferred when e-learning educational tools are not sufficient to support the learning process. Advances in ICT replace traditional classroom meetings with online sessions and lead to a hybrid approach, which is defined as blended distant learning (Varlamis \& Apostolakis 2010). Blended distant learning supports both offline and online learning, offers a bi-directional model of knowledge flow and employs synchronous and asynchronous communication and learning tools such as: email, forum, chat, audio-video conference, presentations, wikis, Whiteboards, Web Tours, e-voting, Applications Sharing, portals, etc. 
The aims of virtual learning communities are usually served by Virtual Learning Environments (VLEs). The most popular VLEs are web based platforms (e.g. Atutor, WebCT, Blackboard, Claroline, Moodle etc.), also known as Learning Management System (LMS) or Learning Content Management Systems (LCMS), which aggregate all or many of the aforementioned tools in order to serve the community needs. In such platforms, teachers and students interact with each other, exchange knowledge in the form of course related documents, assignments, presentation sheets, group assignments etc.

Online 3D virtual environments (3DVEs) have gained the attention of the educational community during the last decade (Corbit 2002, Dickey 2005, Burns 2007). They

offer comparatively easy ways to generate and design visualizations and interactive content and offer possibilities for interdisciplinary collaboration (Leidl \& Rößling, 2007). They provide an answer to the main drawback of distant learning against traditional synchronous learning approaches, which is the lack of social presence and awareness. Online 3DVEs, such as Second Life, OpenSim, Wonderland and Croquet offer better simulation of the interaction in classroom, since they support the use of 3D-avatars, voice chat, lips and other body part movements which can help address the lack of awareness and attract students' and teachers' interest (Konstantinou et al 2009).

As a result, fully immersive massively multiplayer virtual worlds have attracted the interest of researchers and educational institutes. In these worlds, learners themselves construct knowledge through interpreting, analyzing, discovering, acting, evaluating and problem solving in an immersive environment, rather than through traditional instruction (Antonacci \& Modaress, 2008). In order to be applicable to the constructivist educational model, a virtual world needs at least two essential capabilities: a) telepresence (via avatars) and b) immersion in the virtual world (Dede, 2005). These capabilities are less prominent in traditional LMS' than in immersive 3DVEs. On the other side, virtual worlds are not designed for managing learning content. Although one can include streaming media (audio and video), storing and managing documents "in-game" is still cumbersome. The import and export facilities for common file formats - e.g., Word, PDF, or PowerPoint - are currently only rudimentary.

Some recent approaches try to combine the features of Learning Management Systems (LMS) and Virtual Worlds. Applications like Sloodle (Kemp \& Livingstone 2006), (Kemp \& Livingstone 2008) integrate web-based Course Management Systems into virtual environments and try to benefit from both sides. They combine the improved social interaction capabilities of Virtual Worlds and the contentmanagement qualities of LMS, which are more suitable for asynchronous communication, simple tests and persistent storage of related documents. Sloodle, uses the Moodle open source system and Second Life's connectivity features to mirror web-based classrooms with in-world learning spaces and interactive objects.

The Dubai-Korea Virtual Cultural Exchange Project (Surridge \& Shammas 2009) uses Sloodle as a learning management system and Second Life as a virtual space for all the related activities. This project was conducted in 2008 for a seven week class for learning English as a Second Language. In the EU funded research project COMmunity of integrated Blended Learning in Europe (COMBLE) research institutes from Europe organized online course in Second Life supported by a Moodle LMS (Ryberg et al, 2008).

Our work is in the same direction. We employ Sloodle for bridging the gap between Second Life and Moodle. However, in contrast to the aforementioned approaches, we 
follow a totally virtual blended learning, and support an open learning community. The community members have no prior knowledge of each other and the course design follows a seminar-like framework rather than a strict academic curriculum. The evaluation that we perform in section 5 studies the special parameters of our approach and their effect in students' behavior and in the acceptance of the proposed community.

\section{Course design}

The main aim of this work is to create a bridge between widely accepted e-learning platforms and popular 3D virtual environments (3DVEs) and consequently facilitate learning communities to move towards 3D worlds. Following the initial concept of a platform for learning Physical Sciences we developed "Physical Sciences Virtual Classroom" which is a hybrid electronic environment that combines Moodle and Second Life. We designed 3 courses, entitled "Brewing", "Coulomb's Law" and "Solar System" for the science of Chemistry, Physics and Astronomy respectively. The courses have been designed in order to allow students of different of ages and without prior knowledge to attend them.

In the following we focus on the design of "Brewing", which is the first course delivered in our platform. The course combines an online lecture given in the virtual classroom in Second Life by a graduate student of Food Science and Technology, several presentation slides and additional reading material, a student assessment test and a 3D representation of a brewery. The main lecture and the presentation slides illustrate the history of brewing, present the details of each step of the brewing process and provide information on the nutritional value of beer. The lecture inside Second Life is interactive, in an attempt to resemble as much as possible to a typical "course in the classroom". During the lecture, the teacher encourages student participation and dialogue by asking questions and making comments and remarks on the types of beer, their drinking habits etc. At the end of the lecture, all attendants receive an invitation to a virtual visit to a brewery. In their walk inside the $3 \mathrm{D}$ virtual brewery, students are able to watch each step of the brewing process, e.g. malting, brewing, fermentation etc. The primary aim of the student assessment process was to assist participants to revise the knowledge acquired during the online course and to search in the assorted reading material. So, in a separate session, all attendants were able to pass an online test comprising question related to the brewing process.

\subsection{Online course}

The first online course had 10 attendants spanning a wide range of ages (from 20 to 40). Each one of the participants joined the virtual learning community from his/her own place and has been logged both in the 3DVE (SL) and in the e-learning platform (Moodle). As we will explain in the following section, the two platforms have been adjusted in order to exchange necessary data and provide links between each other, thus creating a seemingly homogeneous learning environment for the attendants. Students, are able to easily switch between the 3DVE and the text based e-class environment and attend the various activities in their preferable platform. 


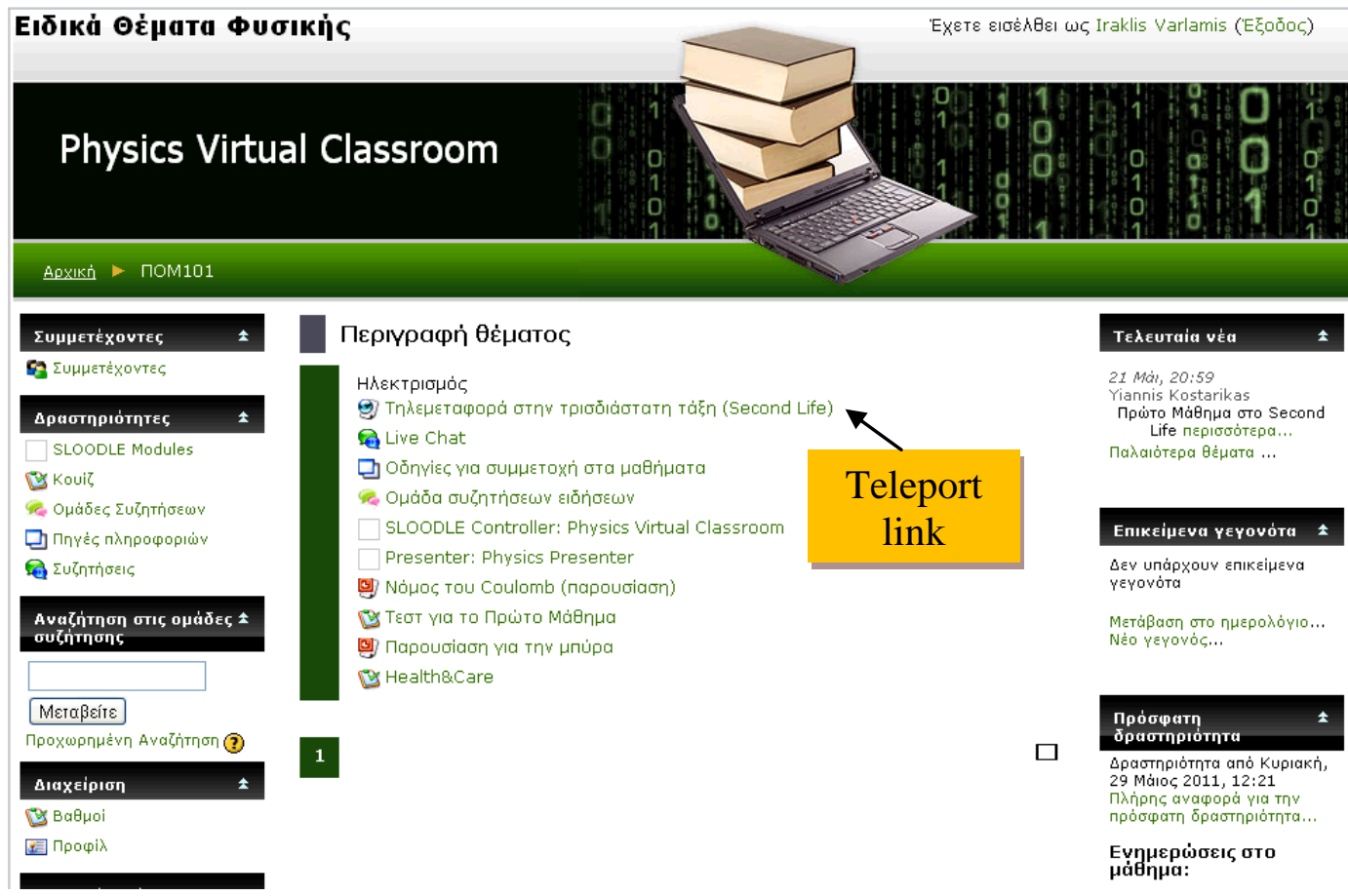

Figure 1. Moodle welcome screen

In a predefined meeting time and point in Second Life, the teacher and a technical assistant were waiting for students outside the virtual classroom. The students can either login to Second Life and teleport to the virtual classroom, or login to Moodle and then teleport to the meeting point by clicking the appropriate link (see Figure 1). They used voice, text chat (which was common in SL and Moodle) and private messaging in order to welcome students and facilitate them in their first steps in the virtual world. Inside the virtual classroom, students sat in their virtual desks, from where they could see the virtual whiteboards and could hear their teacher (see Figure 2). The main whiteboard was used for projecting the presentation slides. However, a secondary whiteboard allowed the teacher to project videos and images or to display an interactive web browser. During the lecture, both teacher and students were able to communicate with voice (public) and text chat (public or private).

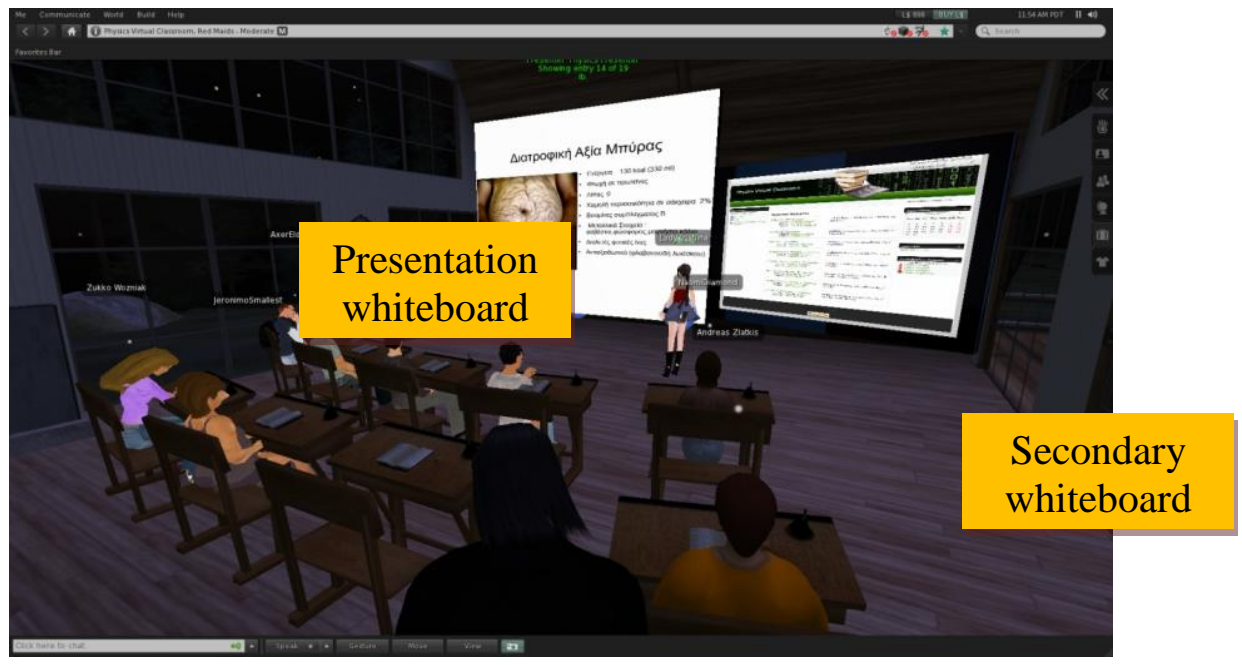


Figure 2. The virtual classroom in Second Life (from the technical assistant point of view)

After the virtual lecture, all students were teleported to the virtual brewery (see Figure 3), which was located in a different SL island. Inside the virtual brewery, students had the chance to view the different stages of beer production from malting to fermentation. The virtual brewery contained 3D virtual replicas of all the devices used in brewing (e.g. mash tun, kettle, hopback, kegs etc), and students were able to follow every step of the process by clicking on an item, reading or listening to recorded info and searching for the next item in the process. The teacher and the technical assistant was there to assist them in every step, or to answer questions that relate to the course subject.

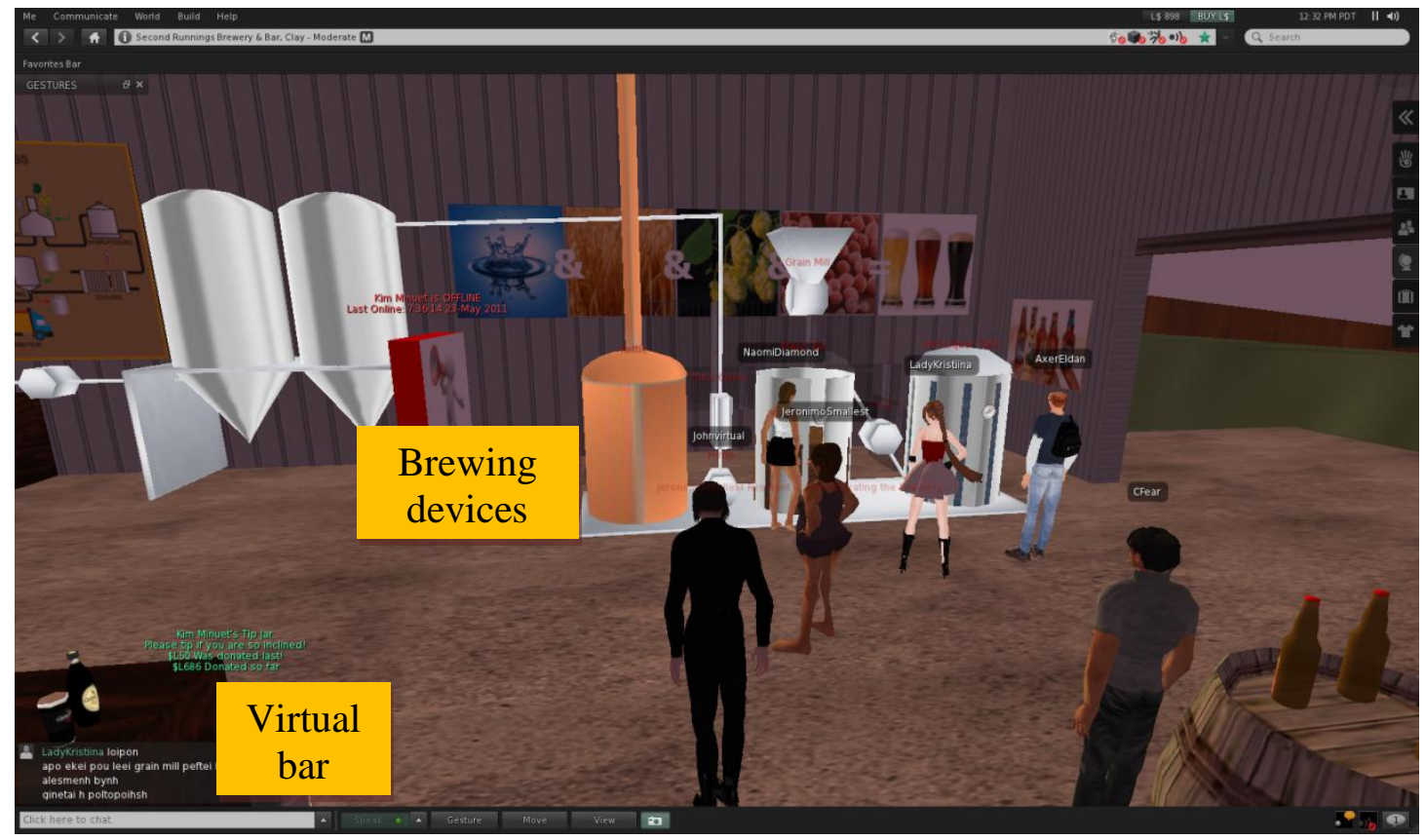

Figure 3. A visit to the virtual brewery

At the end of the brewing process, in a corner of the virtual brewery, a virtual bar was there for the students who managed to pass through the whole brewing process and served them with their virtual beer. Depending on each student's decisions during the brewing process, a different type of beer was created.

\subsection{Student assessment}

After the visit to the virtual brewery, students were able to return to the virtual classroom and answer an online test. The questions (multiple choice questions or correct/incorrect statements) covered both the online lecture and the information provided during the visit to the virtual brewery. The test was accessible both through Second Life or Moodle and was available for another 24 hours after the end of the course in order to facilitate students that needed to access the reading material.

\section{Implementation}

The platform supporting the virtual learning community comprises several synchronous and asynchronous e-learning tools. Additionally, it combines the merits of the 3D virtual environment of Second Life, which offers visualization of objects, 
synchronous voice and chat, virtual participation via avatars etc. with those of the popular e-learning community platform Moodle, which offers several synchronous and asynchronous tools for teacher and student communication and facilitation, presentation, apprehension and assessment of acquired knowledge. The two platforms have been technically bridged in order to allow students to easily switch between them and seemingly participate in a homogeneous virtual educational environment that offers access to online reading material, web search services, online text or voice discussions, etc. The result of this platform merging, as shown in the analysis of a survey performed among the community members, is that attendants had most of the facilities that exist in a real-world classroom, whilst they stayed at home. Moreover, they had access to online resources and other facilities which are typically available only in asynchronous, web-based, e-learning environments.

\subsection{Moodle}

Moodle (Modular Object - Oriented Dynamic - or Developmental - Learning Environment) is a Course Management System which has been designed to support virtual communities that capitalize on social constructive learning. Its main characteristics, as stated by its fullname, are:

- Modular: Moodle offers a large collection of independent pieces of code (modules) which support the learning process. The contributed modules can be easily added or removed from any Moodle release and can be customized through an easy to use administration interface. This increases the flexibility of the platform, and makes it appropriate for a wide range of educational scenarios from self-learning to virtual learning communities. Some examples of Moodle's modules are e-mail, synchronous text chats, discussion groups, quizzes, labs, assignments, glossary, etc. The Moodle supporters' community comprises programmers and educators, who frequently release new publicly available modules that cover almost any educational requirement.

- Object - Oriented: Moodle capitalizes on the use and re-usability of learning objects. Each piece of educational content (material, activity etc.) in Moodle corresponds to a self descriptive learning object, which can be easily customized or adapted to the needs of a specific course. This allows educators to create and share libraries of learning objects and improves constructivism at teacher level, since they are able to design their own teaching strategy and easily arrange contents and activities into logically designed courses.

- Dynamic or Developmental: Moodle is a dynamic and continuously evolving platform. It allows storage of user data (personal profile, usage data, assessment information etc) in a properly designed database schema and offers performance analysis tools for students and teachers. By configuring a rich set of properties, the environment can be easily adapted to each individual's needs by adding or removing material, tools and modules.

The most important advantage of Moodle, is that it can be accessed through a web browser and needs no additional software to be installed in the students' of teachers' computers.

In its current deployment, our "Physical Sciences Virtual Classroom" runs over Moodle 1.9.7, which has been installed over a LAMP web server installation (active URL: http://www.medialab.edu.gr/dk/vclass/). The default set of Moodle plugins has been extended with a calendar and an online text chat.

A course on "Brewery" has been created and all the related electronic reading material has been added to the course page. The material comprises the presentation 
slides, electronic documents and useful links to online resources. Every student and teacher was able to connect to the Moodle web site and apply for a login account. After approval users are able to login to the platform, customize their profile, communicate with each other using private messages, access the online text chat and the asynchronous forum. They can also download and study the educational material, answer quizzes or view their performance in courses. Depending on their roles (teacher, student, course creator, administrator and visitor) users have access to specific parts of the online content, activities and course administration tools.

\subsection{Second Life}

Second Life (SL) is a 3D virtual environment, which is based on the typical clientserver architecture. Any user running the free SL client and having an internet connection is able to create an account and connect to SL servers around the world. Inside the virtual environment, users are able to create and customize their own avatar in a few clicks. If they decide to pay a small fee, they are able to create their own worlds in one of the SL servers, and start receiving their weekly virtual salary (of 400 linden dollars). Inside Second Life a user is able to meet and talk with friends, shop virtual items, listen to music, visit other users' buildings or create her own objects and buildings. Users are able to teleport from one island to another (one server to another) gather with other users and exchange messages, items and services.

From its beginning, Second Life has been used for educational purposes, since it offers several asynchronous communication tools, such as voice or text chat and advanced multimedia capabilities such as video and slide projection, 3D visualizations etc.

The virtual classroom of our community has been created from scratch. A slide projector and a multimedia screen have been added, as well as sitting desks for every student. The virtual brewery that has been employed in our virtual visit, has been created by members of the Second Life community.

\subsection{Bridging the two worlds}

In our attempt to bridge the virtual world and the e-learning platform we faced a hard technical challenge, which was to create the links between Moodle and Second Life platforms and thus seemingly integrate the two platforms in a homogeneous environment.

The first step towards bridging the two platforms was to install SLOODLE (Simulation Linked Object Oriented Dynamic Learning Environment), a Moodle addon which facilitates data transfer between Moodle and Second Life platforms. The integration of the two platforms required the downloading of the Sloodle Toolset, which was performed inside the Second Life platform. For this purpose, the administrator of the community, first logged into Second Life and added the Sloodle Toolset to his inventory, then teleported himself to the virtual classroom and installed Sloodle by simply putting the item into the classroom floor. Finally, he entered the URL of his Moodle installation and a new set of options has been added in his Moodle administration console under the option "Sloodle Controller". This process took us approximately 15 minutes and was fairly simple, as described above.

The toolset under the "Sloodle Controller" option in Moodle's administration console comprises several useful tools, which are made available in both platforms: a tool for assignments submission (Prim Drop), a chat service (Web Intercom), a multiple choice question service (Choice), a glossary (Meta Gloss), an object for making presentations (Presenter), a special Quiz Chair, a 3D booth for registering user avatars 
in second life and linking them to Moodle profiles (RegEnrol Booth) etc. The administrator can simply activate or deactivate a tool in the options of Sloodle Controller. From this same controller, the administrator is able to add the virtual objects in the Second Life classroom. All the necessary configurations for linking objects between the two platforms are automatically adjusted.

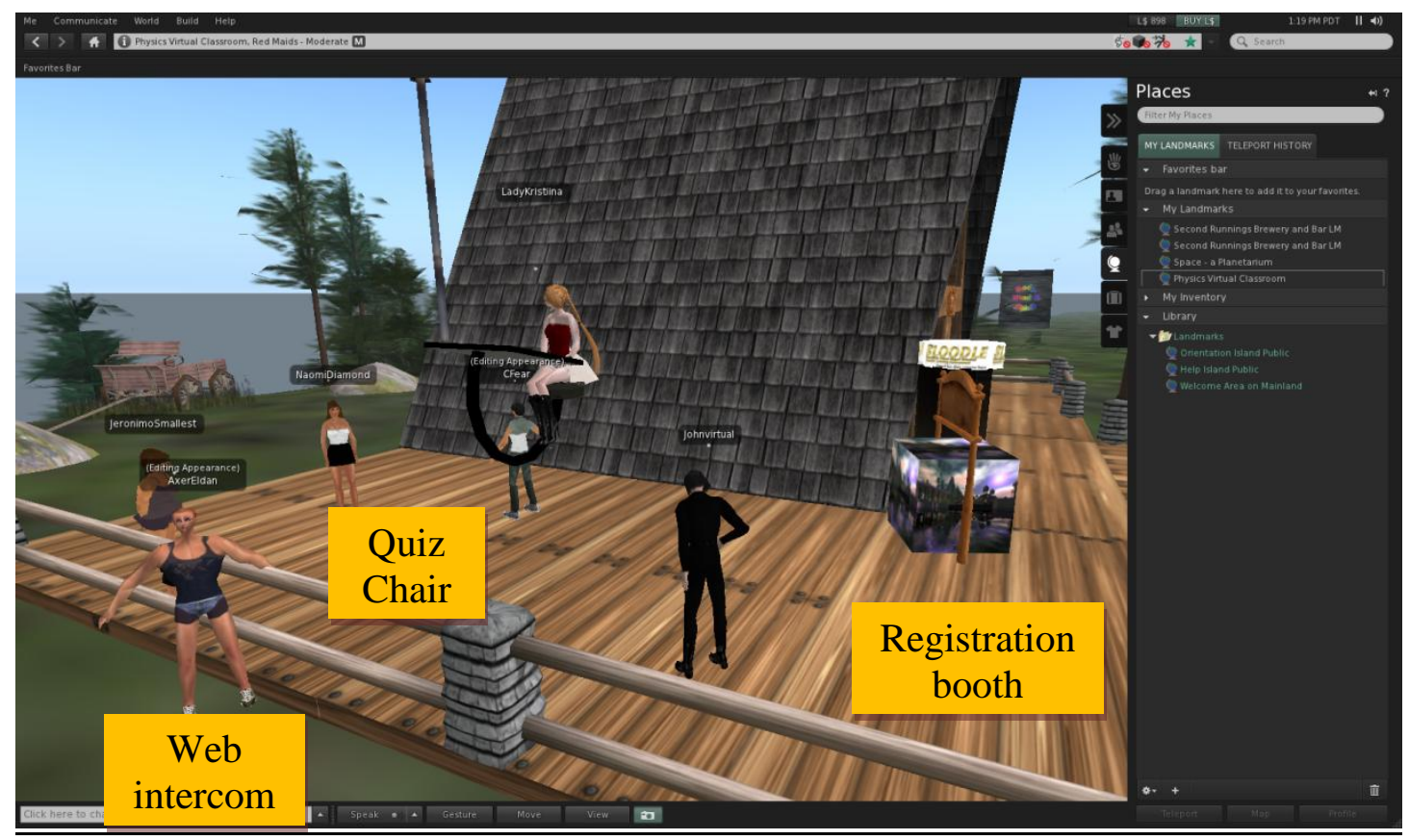

Figure 4. The outside of the virtual classroom

For the first course we employed the following tools (see Figure 2 and Figure 4):

- RegEnrol Booth: A virtual booth in Second Life, where users can link their SL avatar to their user profile in Moodle with a simple click. After this registration process, any actions in the virtual world are mapped to the respective Moodle tools (e.g. chat, answering a test, getting a grade in a course etc.).

- Sloodle Presenter: The virtual whiteboard where the course slides are projected. The presentation has been created by the teacher and uploaded in Moodle.

- Web intercom: This tool allowed the connection between Moodle's and Second Life text chat services, thus creating a common chat room accessible from both platforms.

- Quiz Chair: At the end of each lecture, students sit in the Quiz Chair and answer the questions. A correct answer moves the virtual chair to a higher level, whereas wrong answers lower the chair. As a result, a series of successful answers will elevate the above his classmates.

\section{Evaluation}

At the end of the first course, all students were asked to evaluate various parameters of the course and the platforms by completing a questionnaire. The aim of the questionnaire was to examine the users' perception of the virtual course and the linked platforms. Questions aimed to evaluate the educational value of the virtual course and its psycosocial effects and to identify usability and technical problems.

\subsection{Pedagogical evaluation}


The results in Figure 5 showed that the majority of the students were excited by the idea to participate in a virtual online course in a 3DVE. Almost all found the course very or extremely interesting and understandable. They also liked the idea of 3D simulation and found it very helpful in understanding the brewing process. Finally, they all stated that will be happy to use the platform in the future.

In comparison to a course in real a class, the opinions were contradicting. According to the negative opinions: the virtual course was not able to replace the immediate contact with the teacher, it was difficult for the teacher to interact with students and make them more active, students' attention can be easily distracted since they are sitting in their own places and the tutor is unaware of it. The 3DVE provides a good simulation of the real class environment, since it gives the ability to the teacher to use an avatar and his/her own voice during the presentation and the same holds for students. Although private text messaging between students is allowed and cannot be controlled by the teacher, voice chat can be perceived by anyone inside the classroom as happens in a real classroom. On the other side, the distraction of students' attention in modern classrooms or computer labs is a reality (Barkhuus 2005, Fried 2008) and virtual classrooms cannot avoid this fact. However, a shorter lecture and more interactive activities that encourage student creativity can keep students' attention in a high level.

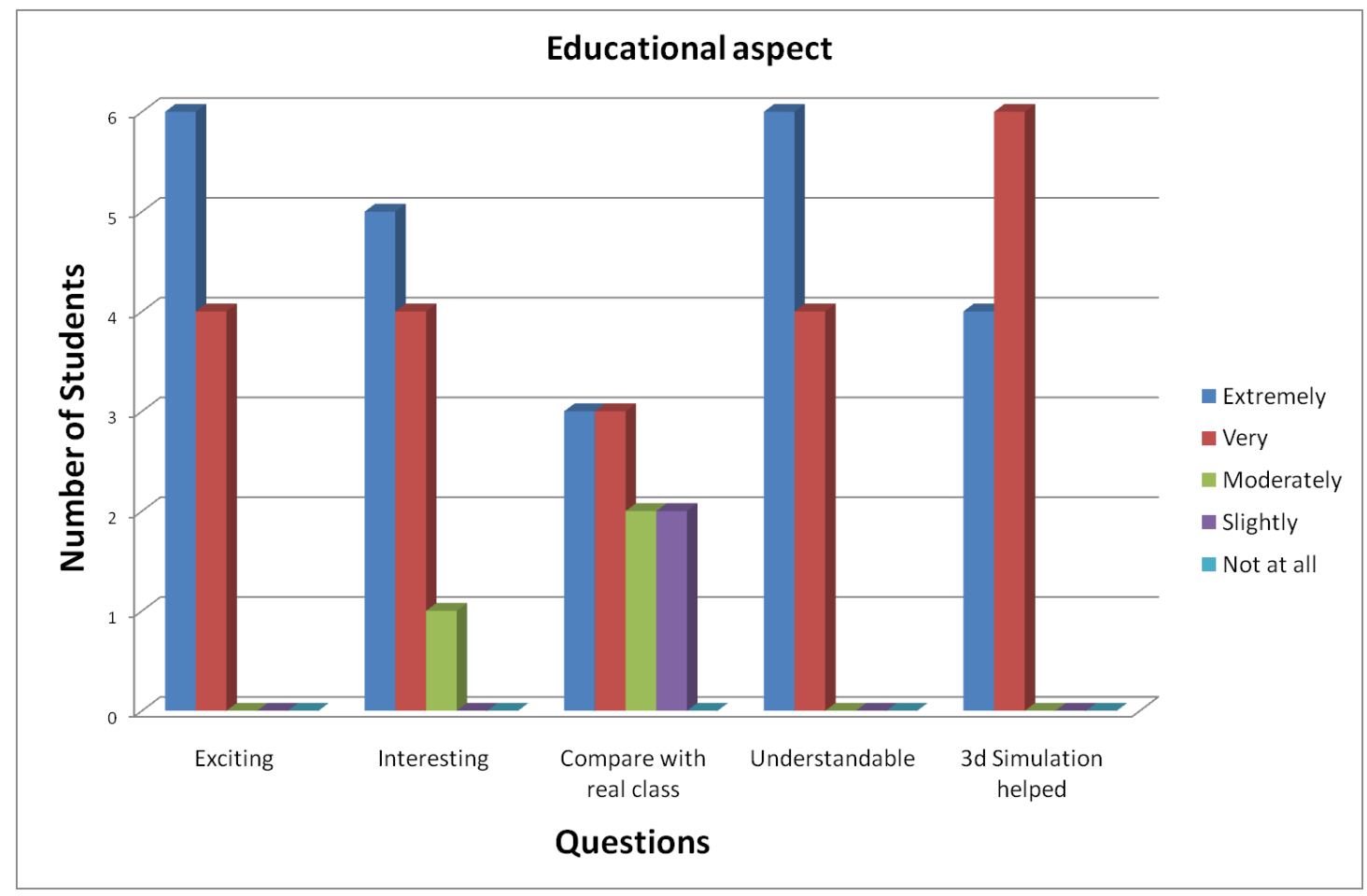

Figure 5. Results on the educational aspect

\subsection{Psychosocial evaluation}

The results of the evaluation of the psychological aspect (see Figure 6) show that most of the students had the feeling of presence inside the virtual space. As far as it concerns the choice of avatar, half of the attendants choose an avatar close to their physical image and the other half choose a completely irrelevant avatar. Most of the students felt safe and confident inside the virtual place, although most of them have never met their classmates before in the real or virtual world. 


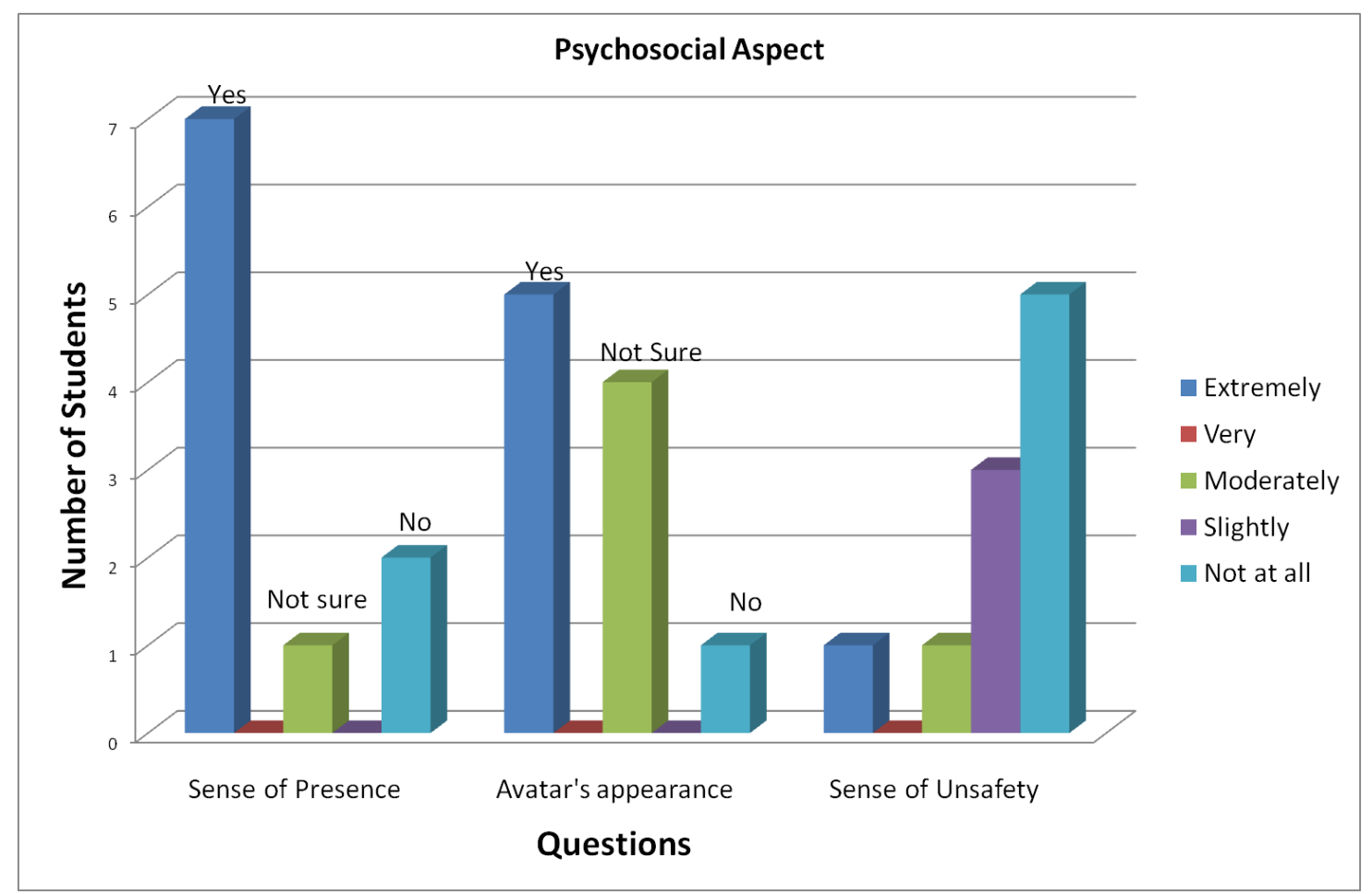

Figure 6. Results on the psychosocial aspect

Four out of ten students had never used Second Life before. Three of them felt a little unsafe from being together with people they had not met before in real life. Despite the fact that the remaining six students had used Second Life a few times, two of them felt a little unsafe in the virtual world. One student said that during his stay in the virtual space he felt he could easily lose touch with reality.

All students pointed out that they would like to use Second Life or another virtual world in the future. Half of them would do it for a learning process, three for gaming and two for meeting new people and socializing.

\subsection{Technical - Functional Evaluation}

Almost all students logged on easily to the virtual world and most of them were happy from their navigation in the virtual world (see Figure 7). The majority of the students feel comfortable to use the platform in the future without the aid of the teacher or a technical assistant. However, one student stated it would be too difficult for her. Different things inside the virtual world attracted the interest of students: four were drawn by the overall image, three were more impressed by the 3D representation of the brewing process, others liked the sound, the choice of avatar or the movement within the space. 


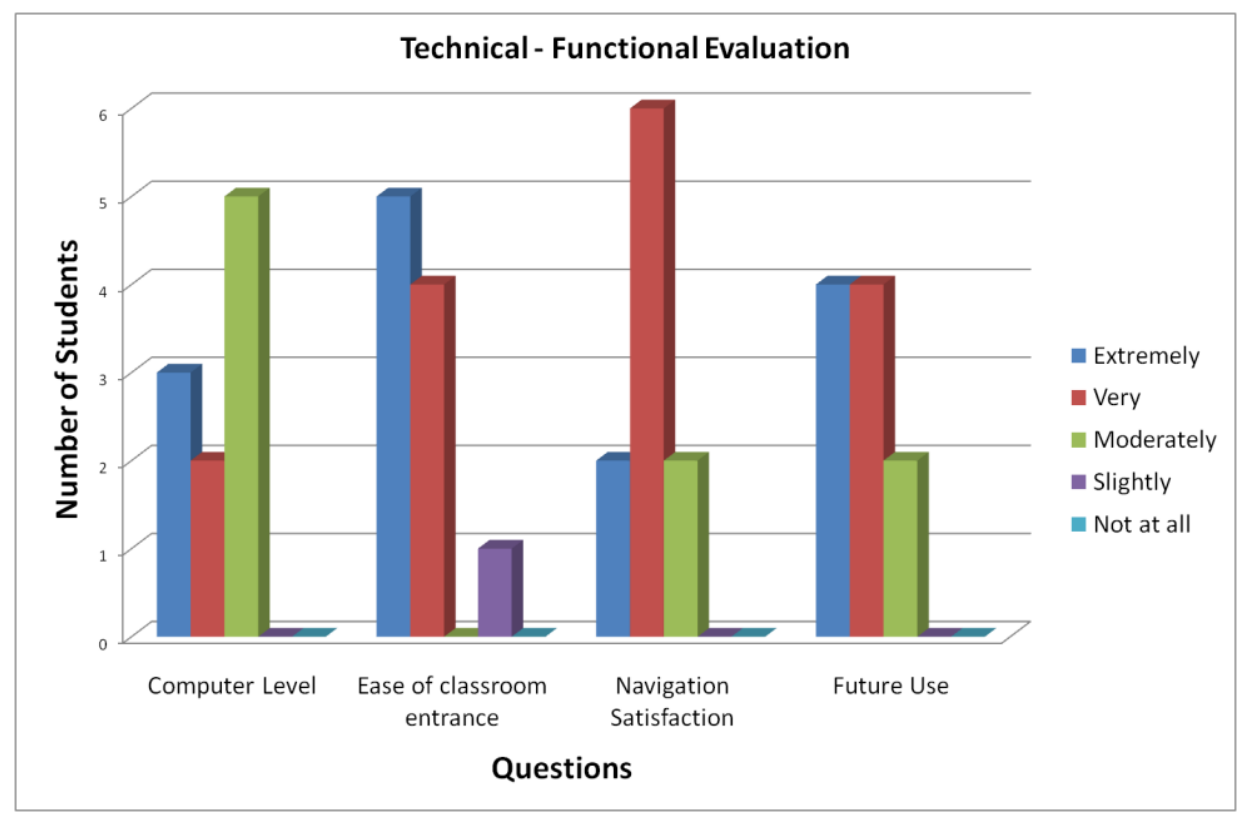

Figure 7. Results on the technical aspect

Despite the overall satisfaction, students faced several technical difficulties during the lesson, which were mainly due to their limited technical experience, and to insufficient equipments. Most students had difficulties in activating voice chat, but finally managed to activate it after communicating, using text chat, with the technical assistant. For those who had no microphones, text chat was the only option. Audio communication was the feature that most students would like to be improved. The avatar graphics, the ease of navigation and the quality of 3D graphics were also features that need improvement according to students.

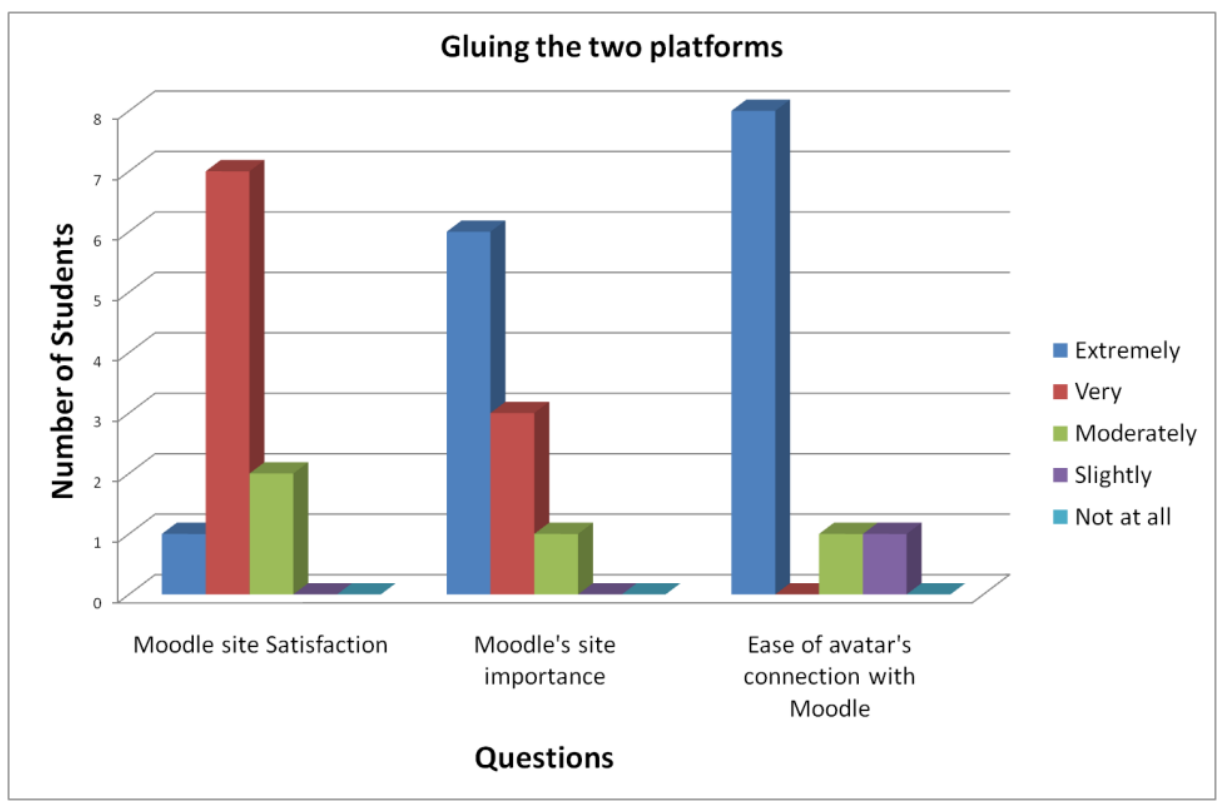

Figure 8 . The evaluation of platform merging 
As far as it concerns the Moodle site, students were satisfied overall. The majority of them found it easy to connect their Moodle profiles to their Second Life avatars and stated the presence of the two-dimensional platform is important (see

Figure 8). The tools and educational content were found necessary. Finally, they reported that a two-dimensional platform strengthens the sense of safety that weakens inside the virtual world. All students agreed the Moodle platform was integral in facilitating easy access to the subject matter, news, announcements, tests and grades. One person mentioned that the Moodle platform was necessary because it offers quick access to content and is closer to what most people are familiar with, while another stated it can provide a good introduction and acquaintance with the object of study, plus an easy transportation to the virtual classroom by means of a simple click.

\section{Conclusions}

This paper presented a platform for supporting blended learning in virtual learning communities. The platform unifies a popular LMS and an internet based 3DVE and allows the community members to perform every learning activity, from virtual lectures to exams and assignments, online. The first experiences of users from this unified platform are positive and show that users prefer to use LMS because of its simplicity and speed of access, but are also attracted from the virtual environment, the interactivity and 3D visualization it offers. The next step of our work is to evaluate the platform in more courses and learning communities' cases and adapt this totally virtual experience to the needs of blended learning.

\section{References}

Antonacci, D. M., Modaress, N. (2008). Envisioning the Educational Possibilities of User-Created Virtual Worlds. AACE Journal 16 (2), pp. 115-126

Barkhuus, L. (2005). Bring your own laptop unless you want to follow the lecture: Alternative communication in the classroom. Proceedings of the 2005 international ACM SIGGROUP conference on Supporting group work (GROUP '05). ACM, New York, NY, USA, pp. 140-143

Burns, B. (2007). Darkstar: The Java Game Server, August 2007, O'Reilly

Corbit, M. (2002). Building virtual worlds for informal science learning (SciCentr and SciFair) in the active worlds educational universe (AWEDU). Presence: Teleoper. Virtual Environ. 11, 1 (February 2002), pp. 55-67

Dede, C. (1995). The Evolution of Constructivist Learning Environments: Immersion in Distributed, Virtual Worlds, Educational Technology, 35 (5), pp. 46-52

Dickey, M. (2005). Three-dimensional virtual worlds and distance learning: two case studies of active worlds as a medium for distance education. British Journal of Educational Technology, 36 (3), pp. 439-461

Fried, C.B. (2008). In-class laptop use and its effects on student learning. Computers \& Education, 50 (3), pp. 906-914

Graham, C. R. (2005). Blended learning systems: Definition, current trends, and future directions. In Bonk, C. J.; Graham, C. R. Handbook of blended learning: Global perspectives, local designs, San Francisco, CA: Pfeiffer, pp. $3-21$

Kemp, J., Livingstone, D. (2006). Putting a Second Life 'Metaverse' Skin on Learning Management Systems. Proceedings of the Second Life Education Workshop at SLCC, San Francisco, August 2006, pp. 13-18 
Kommers, P., Rödel, S., Luursema, J.M., Geelkerken, B., Kunst, E. (2003). Learning Surgical Interventions by Navigating in Virtual Reality Case Spaces. International Conference on Computational Science 2003, pp. 1015-1024

Konstantinou, N., Varlamis, I., Giannakoulopoulos, A. (2009). The use of 3D virtual learning environments in the learning process. In Lionarakis, A. (ed.) Proceedings of the 5th International Conference in Open and Distance Learning 2009 (ICODL 2009), Athens, Greece

Leidl, M., Rößling, G. (2007). How Will Future Learning Work in the Third Dimension? - ITiCSE'07 - Proceedings of the 12th annual SIGCSE conference on Innovation and technology in computer science education, p. 329

Livingstone, D., Kemp, J. (2008). Integrating Web-Based and 3D Learning Environments: Second Life Meets UPGRADE. The European Journal for the Informatics Professional, 10 (3), Citeseer, pp. 8-14

Ryberg, T., Brenstein, E., Pilt, L., Moczadlo, R., Niemczik, C., Dirckinck-Holmfeld, L. (2008). Enhancing Blended Learning - Developing a Community Based Methopedia. In Proceedings of the 7th European Conference on e-Learning: Book of abstracts. ed. Dan Remenyi. Academic Conferences Ltd, p. 59

Surridge, C., Shammas, N. (2009). Using Sloodle: Dubai-Korea Virtual Cultural Exchange Using Sloodle to Support learning and teaching. Retrieved from http://www.sloodle.org/moodle/file.php/1/SLOODLEcasestudy1.pdf

Trapp, S. (2006). Blended Learning Concepts - a Short Overview. In E. Tomadaki and P. Scott (Eds.): Innovative Approaches for Learning and Knowledge Sharing, EC-TEL 2006 Workshops Proceedings, pp. 28-35

Varlamis, I., Apostolakis I. (2010). A framework for the quality assurance of blended e-learning communities. In proceedings of the 14th Annual KES Conference, 8-10 September, 2010, Cardiff, Wales, UK. In: Setchi et al. (Eds.): KES 2010, Part III, LNAI 6278. Springer-Verlag, Berlin Heidelberg 